\title{
A modelling framework for assessing water conservation potentials through demand-based tariff structures from societal and economic perspectives
}

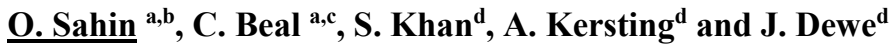 \\ ${ }^{a}$ Griffith School of Engineering, Griffith University, Queensland \\ ${ }^{b}$ Griffith Systems Modelling Group, Griffith University, Queensland \\ ${ }^{c}$ Smart Water research Centre, Griffith University, Queensland \\ ${ }^{d}$ Gold Coast Water, City of Gold Coast, Queensland \\ Email:o.sahin@griffith.edu.au
}

\begin{abstract}
The water resources conditions influenced by population growth, coupled with declining water availability and changes in climatic conditions underline the need for sustainable and responsive water management instruments. Supply augmentation and demand management including pricing are two main policy mechanisms generally utilised by water utilities. However, the question of pricing to change water use behaviour (demand) is a challenging process as they bring additional social and political issues into the already complex management of water resources. The complexity is characterised by many interdependent components and requires the participation of stakeholders in developing management strategies. The key factor of pricing is to calculate a price that reflects the full cost of water consumption and provide incentives for efficient wateruse behaviour, and thereby contributing to the long-term sustainable water resources management. Therefore, stakeholder involvement is crucial to determining the successes and failures of implementing pricing strategies. In the light of the above discussion, this paper presents a participatory framework for achieving greater water conservation potentials through demand-based tariff structures from societal and economic perspectives. The framework provides an appropriate modelling platform for assessing this water tariff (price)-demand-revenue nexus as it explicitly accounts for the feedbacks, interdependencies, and non-linear relations that inherently characterise such systems. Thus, in this research, a participatory System Dynamics modelling (SDM) approach was employed to explore the water demand fluctuations and revenue outcomes by introducing an inclining block tariff (IBT) to residential customers on the Gold Coast. To build the model, we have worked with a range of stakeholders from academia, experts from the water utility and a number of agencies (e.g.: Queensland Council of Social Services, Queensland Competition Authority, Gold Coast Chamber of Commerce), in order to produce a logical simulation model. The SDM tariff modelling incorporates three distinct modules to achieve the specific objectives of the study; these modules considered revenue forecasting; differentiating high and low water users; and demand feedback. The SDM results show that: a) the IBT, where the highest users pay more for using more, is an effective method for incentivising high water use customers to reduce water use through pricing rather than restrictions across the board; b) revenue neutrality can be achieved using an IBT by determining the feedback of customers to the higher cost; c) the IBT represents a successful water demand management and water conservation strategy whereby reducing household costs are an incentive for water efficiency; d) there is also an opportunity for the water utility to vary the proportion of customers that are charged the second block tariff during wet seasons (high water availability) or dry seasons (low water availability).
\end{abstract}

Keywords: Water conservation, demand-based tariff modelling, integrated modelling, system dynamics modelling, stakeholder engagement 
Sahin et al., A modelling framework for assessing water conservation potentials through demand-based tariff structures

\section{INTRODUCTION}

The water resources situations influenced by population growth, coupled with declining water availability and changes in climatic conditions underline the need for a sustainable and responsive water management instrument. There are two main policy mechanisms utilised by water utilities: Demand management (e.g.: water restrictions, pricing and water conservation campaigns) and supply augmentation.

Although a water tariff (pricing) is an important management tool in dealing with challenges of providing water to all citizens at a realistic price and the conservation of water resources, the pricing water services is controversial. The process of water and waste water pricing is inherently complex and usually involves many stakeholders such as different level of governments, regulating authorities, bulk water suppliers, water utilities, and consumers. Consequently, it is hard to reach a consensus on water pricing issues as objectives and expectations of different stakeholders often fluctuate extensively.

According to Whittington (2003), three of the many reasons why there is so little consensus on municipal water tariff issues are: 1) disagreement over the objectives of water pricing and tariff design; 2) disagreement over what would actually happen if different water tariffs were implemented; and 3) no market test for different water tariff structures. Consequently, setting water price requires balancing four key objectives, namely: a) Revenue sufficiency; b) Economic efficiency; c) Equity; and d) Poverty alleviation

Clearly, the question of urban water pricing, water use behaviour (demand) and resulting revenue is not a straightforward process as they bring additional social and political issues into the already complex management of water resources. The complexity is characterised by many interdependent components and requires the participation of stakeholders in developing management strategies. The key factor of pricing is to calculate a price that reflects the full cost of water consumption and provide incentives for efficient water-use behaviour, and thereby contributing to the long-term sustainable water resources management. In this paper, water price refers to selling and pricing treated water services - the price associated with the provision of physical infrastructure and services required to treat and deliver water to homes, businesses and institutions (Brandes et al., 2010). Therefore, stakeholder involvement is crucial to determining the successes and failures of implementing pricing strategies.

In Australia, since1994, movement towards urban water tariffs with a fixed access charge and a volumetric charge based on water consumption (i.e. a two-part tariff) has been encouraged for a number of reasons (NWC, 2011), such as sending price signals to the consumers to achieve efficient water use targets and reduce water consumptions. Inclining block tariffs (IBT) have been incorporated into the variable component of tariffs in all major Australian cities, with the exception of Newcastle, the Gold Coast and Darwin. In NSW and South Australia, a two-step IBT is used, while in all other jurisdictions there are multiple steps, with Busselton Water in Western Australia adopting an eight step IBT (Frontier Economics., 2008). An IBT is a tiered pricing designed to encourage water conservation by charging higher water users a higher price. The Queensland Competition Authority recommends that retailers' prices for water and related services should reflect the least cost of supplying the service and also be fair as reflective prices are important for providing clear price signals to customers, allowing them to make informed choices about consumption (QCA, 2014).

In the light of the above discussion, this paper presents a participatory framework for achieving greater water conservation potentials through demand-based tariff structures from societal and economic perspectives within the City of Gold Coast (COGC). The framework provides an appropriate modelling platform for assessing this water tariff (price)-demand-revenue nexus as it explicitly accounts for the feedbacks, interdependencies, and non-linear relations that inherently characterise such systems. Thus, in this research, a participatory System Dynamics modelling (SDM) approach was employed to explore the water demand fluctuations and revenue outcomes by introducing an IBT to residential customers on the Gold Coast. However, due to the space limit, we only report the outcomes of tariff modelling component in this paper.

\section{APPROACH}

The question of urban water tariff (price), water use behaviour (demand) and resulting revenue is a complex issue and characterised by many interdependent components. This complexity requires a planning process that accounts for these interdependencies, feedbacks and non-linear relationships involved. The interconnectedness of our world requires integrated approaches to resolving complex environmental issues (Hamilton et al., 2015). The integrated modelling approach provides an ideal platform to amalgamate a range of differing methods and perceptions into an encompassing framework to address complex problems. This approach also enables the modellers to use both qualitative and quantitative data while involving a range of stakeholders. Thus, System Dynamics (SD) provides an appropriate modelling framework for assessing this water tariff (price)-demand- 
Sahin et al., A modelling framework for assessing water conservation potentials through demand-based tariff structures

revenue nexus because it can explicitly account for the feedbacks, interdependencies, and non-linear relations that inherently characterise such systems. Thus, in this project, we apply SDM to explore the water demand fluctuations and revenue outcomes by introducing an IBT on residential customers on the Gold Coast.

$\mathrm{SD}$ is a powerful methodology and computer simulation modelling approach, which was originally rooted in the management and engineering sciences (Forrester, 1961). Gradually, the SD approach has evolved and spread into other fields to simulate complex systems behaviour such as in the social, economic, physical, chemical, biological, and ecological systems (Ford, 1999, Sterman, 2000, Fiddaman, 2002, Sterman, 2008, Sahin, 2013, Porter et al., 2014, Sahin et al., 2015, Scarborough et al., 2015).

In building the SDM, a participatory modelling approach was employed following the approach outlined by (Van den Belt et al., 2004, Langsdale et al., 2009, Sahin et al., 2014). Participatory model development can focus on portraying system structure while model simulations reveal system behaviour, which is less intuitive and often the source of confusion. To build the model and raise the shared level of understanding, we have worked with assumptions regarding parameters and responses drawn from a range of stakeholders (including experts from academia, COGC staff, QLD Council of Social Services, QLD Competition Authority and Gold Coast Chamber of Commerce) in order to produce a logical simulation model. Accordingly, the model development flowed through a multi stage process, including 1) Desktop study 2) Problem scoping and model conceptualisation (Project reference group-PRG meetings and expert consultation); 3) SD model development; and 4) Model testing and calibration (Project management group - PMG meeting \& expert consultation).

Essential variables for model operation were identified by reviewing local based literature for region specific inputs and examining the national and international literature for more generic variables and their behaviour as well as consultation with COGC staff. As illustrated in Figure1, there are three research components undertaken concurrently: 1) Social Survey; 2) Water consumption analysis; and 3) Tariff modelling. In this paper, we focus on the tariff modelling component after providing brief information about first two components.

Social Survey provided baseline data on customer water pricing preferences, water conservation drivers and enhancing residential customer engagement. The survey questionnaire for the telephone interviews was specifically designed to capture all of the required information after close consultation with the COGC project management committee. The questionnaire assessed customer satisfaction, feedback on billing information, understanding of billing structures and demographic information. Individual computer assisted telephone interviews were conducted with 800 randomly selected home owners from the Gold

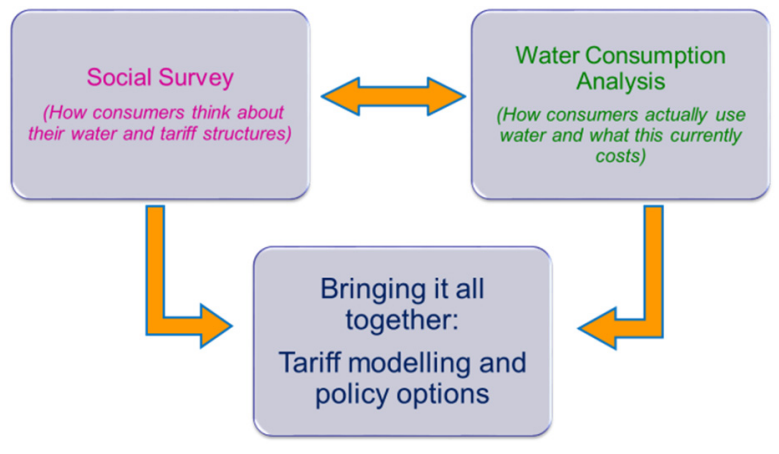

Figure 1. Three research components Coast. To qualify as research participants, respondents had to be over 18, a home owner, and connected to town water. Over 9000 homes were contacted to reach the desired sample size, indicating a response rate of $12 \%$.

Water Consumption Analysis was used to determine water consumption trends over time and compare the average and peak flows from various residential water end-use activities across a range of socio-demographical households. A substantial database of high resolution water consumption data generated from the South East Queensland Residential End Use Study (SEQREUS) was used for this project (Beal and Stewart, 2011). This existing database provided over three years of water use trends from a range of socio-demographic groups in the residential sector. The outcome of this component was input tariff models to predict the potential reduction in peak demand. The SDM was used to track changes to water use when tariff options were being tested with participants.

Tariff Modelling was used to conduct tariff modelling and test alternative policy options as the detailed in the following sections.

\subsection{System Dynamics Model development}

Based on the information from the previous components (Social Survey and Water Consumption Analysis), an SDM was developed. Two-block tariff with high - low cut-off points for the blocks based on responses from survey $(80 \%$ Block1 and 20\% Block2 cut-off points for the low/high user groups were the most favourable) and frequency distribution of GC water consumption identified the top $20 \%$ to consume a large proportion of 
Sahin et al., A modelling framework for assessing water conservation potentials through demand-based tariff structures

water. Tariff modelling incorporated three submodules, which are linked to each other and interact together as a result of the interdependencies between these components:

1. Revenue forecasting module for understanding the impacts of Block 1 threshold and related price changes on the utility's revenue from each water use cluster (Figure 2). The revenue is a function of the number of customers, the volumetric and the fixed charges applied to the revenue aggregates both volumetric - fixed (sewerage and water) charges. The revenue increases (or decreases) depending on the changes in the price level and the water use pattern.

2. Water bill submodule is designed to understand how a price increase would affect the water consumption and the average household water bill for each water use cluster. The model calculates the total bill for a customer by taking into account the total volumetric charges, which is a function of Block1, and Block2 charges, and the fixed charges. When the Block 2 price is applied for billing, the water use fluctuations over time - due to a price increase and the resulting variations in a customer bill - are calculated. The model outputs enable users to make comparisons between the water bills for each water cluster under a range of scenarios.

3. Demand feedback submodule estimates the average water use level per household for each water use cluster by considering the changes in price level, the water use threshold, required time to adjust demand and the demand rebounding time. The model calculates the extent of the customers' response to a price change. As part of a new tariff structure, the use of Block 2 price, and/or an increase in price level per kL, would potentially send a signal to customers to encourage them to use less water, this, in return, would also result in a reduction in their water bill. To incorporate a time varying elasticity into the model, the changes in demand were dynamically computed. The model is designed to simulate the impacts of -0.51 elasticity on water use exceeding Block 1 threshold. This price relationship is, of course, more complicated. When establishing a new pricing regime, a water service provider and its governing body needs to carefully consider the actual sensitivity of water demand to price, which means considering the price elasticity of demand. Water is less inelastic than many generally think. Espey et al. (1997) reviewed 162 estimates of the price elasticity of water that were made between 1963 and 1993. They found an average price elasticity of -0.51 . This is a measure of the expected change in demand when price increases by 1. Similarly, Dalhuisen et al. (2003) analysed 300 studies conducted over the past 20 years and found an average price elasticity of -0.41 (Espey et al., 1997, Dalhuisen et al., 2003).

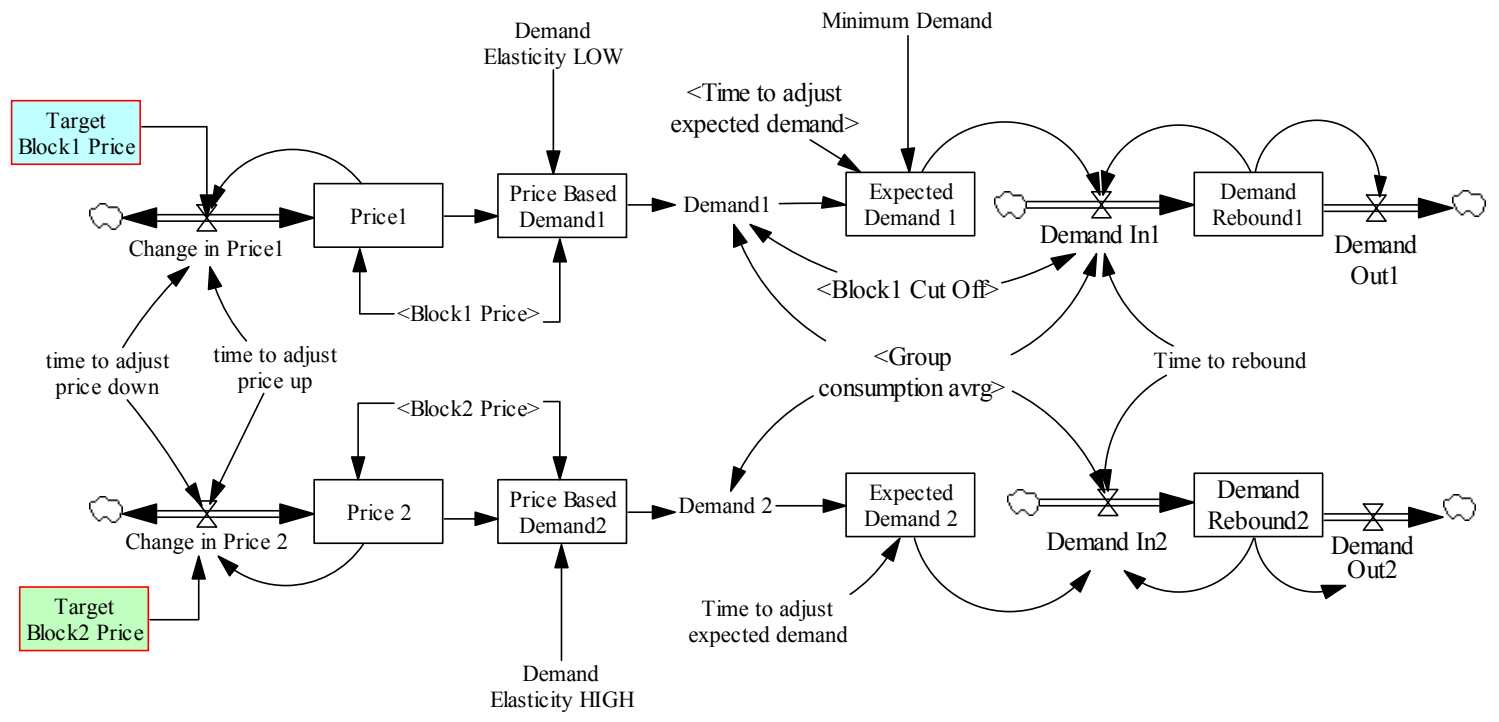

Figure 2. Revenue forecasting submodule

The SDM simulates current and future conditions by considering the effects of water charges, water use and demand. Simulation involves determining the effect of decreasing one or more key factors and simultaneously increasing one or more other key factors in a decision model. That is, the model deliberates various scenarios and alternatives (i.e. Block 1 threshold, water charges, Block 1 and Block 2 charges, demand elasticity), and provides better visualization of how water use, average household bills by water use categories and revenue would vary in the system over time, including any feedbacks that might cause unexpected changes in other parts of the system. 
Sahin et al., A modelling framework for assessing water conservation potentials through demand-based tariff structures

\subsection{Key assumptions and scenarios}

In any new policy/strategy introduction, the key question is: what will happen when this particular policy/strategy change is implemented? Developing and using an SDM can assist decision/policy makers in their deliberations to make realistic decision over a range of policy alternatives. To do this, like all modelling, there are some assumptions made. The water charges as of July 2014 used to calculate a typical household bill on the Gold Coast: fixed sewerage charges \$ 725.12 household/year; fixed water charges \$212.08 household/year; and water consumption charges - \$3.53 kL.

In this project, after consultation with the COGC experts and using findings of the social survey and water consumption components of the research, 8 scenarios were developed to demonstrate the impacts of the key variables on the water price-demand-revenue system (Table 1). However, the SDM enables users to modify key variables in the model to test a large number of scenarios when needed. Scn1 represents the current tariff and provides a baseline scenario from which comparisons are made. Other scenarios, Sn2-Scn8 explore a range of combined tariff structures (fixed charges combined with IBT) which will be detailed in the results section. $\mathrm{B} 1$ and $\mathrm{B} 2$ represent Block 1 and Block2 respectively.

Table 1. Eight tariff scenarios used in the modelling

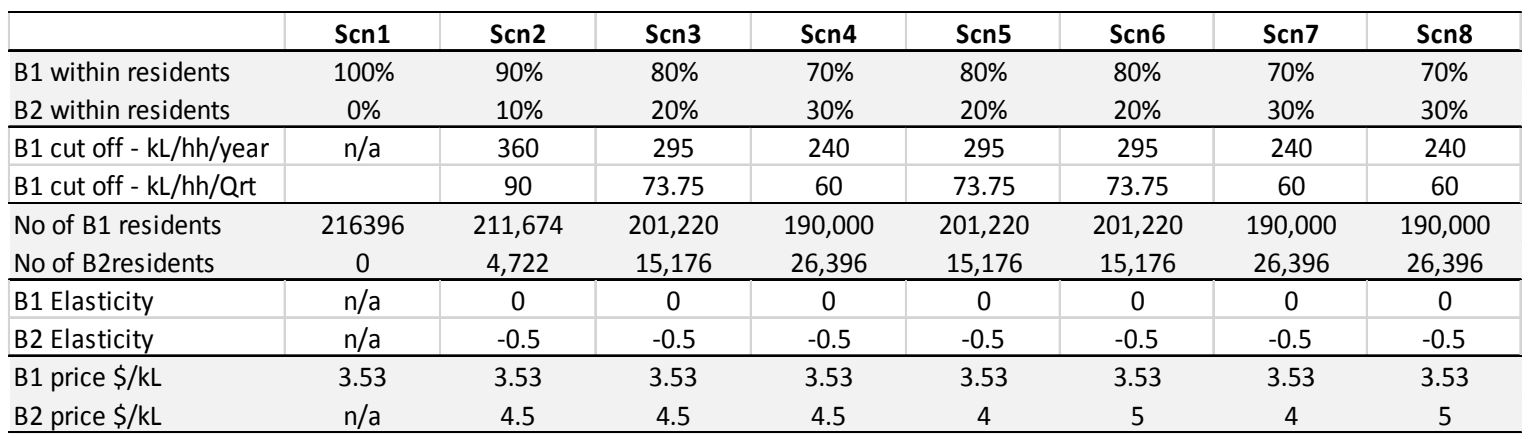

\section{RESULTS}

The Social Survey findings show that the majority of respondents (over $50 \%$ ) prefer a lower fixed water access charge and a higher usage charge. For this preference, the respondents have a range of reasons: a) $40 \%$ people should pay for the water they use; b) over $25 \%$ - a fairer way of paying for water; c) less than $25 \%$ - don't use much water; d) about $6 \%$ - easier for managing my budget. $52 \%$ of the respondents were supportive or extremely supportive of a "two-step" pricing approach where very high water users would pay more for water than low to average water users. $60 \%$ of the respondents think that high water users should be targeted for the second step (higher price).

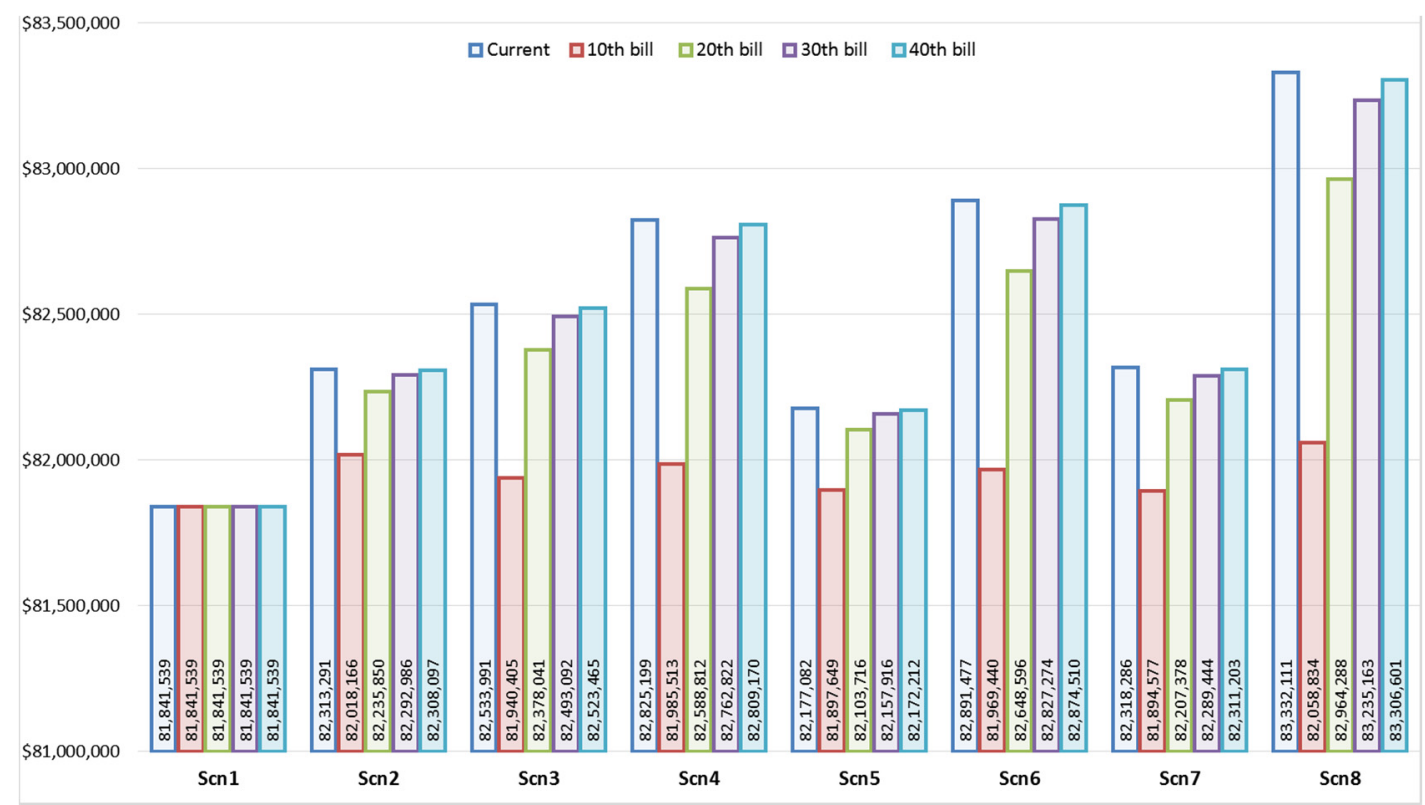

Figure 3. Quarterly revenue comparison under eight scenarios over five decadal billing cycles 
Sahin et al., A modelling framework for assessing water conservation potentials through demand-based tariff structures

Based on the surveyed customers' preferences and the water consumption data, the total quarterly revenue projections for each scenario are presented in Figure 3. Scn1 depicts the current structures; therefore the revenue levels do not fluctuate over time. Scn2-Scn8 reflect a range of IBT conditions as discussed in previous sections. In these scenarios, as seen in Figure 3, the revenue fluctuates over time due to the Block 2 price, which affects the water use level of the customers exceeding the Block 1 threshold. Depending on the threshold and the price level, the revenue from these seven scenarios (Scn2-Scn8) fluctuates at varying degrees. The Scn8 generates the highest revenue $(\$ 83,332,111)$, while Scn5 generates the smallest revenue $(\$ 82,177,082)$. This means that, compared to current tariff structure $(\operatorname{Scn} 1), \operatorname{Scn} 8$ would create an additional revenue of $\$ 1,490,572$ per quarter while Scn5 generates additional $\$ 335,543$ per quarter. For Scn8, this additional revenue translates to $56.5 \$ / \mathrm{hh} /$ quarter increase in high water use customers' bill (26,396 households). For Scn5, this increase would be $12.7 \$ / \mathrm{hh} /$ quarter affecting 26,396 high water use customers.

The impacts of the IBT scenarios on various water user groups are simulated as shown in Figure 4 . The comparison between the existing tariff structure and the proposed IBT tariff structures is shown for four water user groups across Block 1 and 2. The differences can be observed between the two blocks of water users (less than and greater than $250 \mathrm{~kL} / \mathrm{hh} / \mathrm{y}$ ). First twelve water user groups (less than $250 \mathrm{~kL} / \mathrm{hh} / \mathrm{y}$ ), which comprises over $70 \%$ of total COGC customers, will not observe any changes in their bills as these customers will not be affected Block 2 charges under any scenarios tested. For the higher water users exceeding $250 \mathrm{~kL} / \mathrm{hh} / \mathrm{y}$, their quarterly water bill could increase by $\$ 195.50(\mathrm{Scn} 8)$ more than they are currently paying.

\begin{tabular}{|c|c|c|c|c|}
\hline \multirow[b]{2}{*}{ SCN8 } & \multicolumn{3}{|c|}{$\begin{array}{l}\text { - Small family }=<20 \mathrm{~kL} \\
\text { Big family }=<250 \mathrm{~kL}\end{array}$} & \multirow{2}{*}{$\begin{array}{l}\text { - Average family }=<170 \mathrm{~kL} \\
\text { High water user }>770 \mathrm{~kL} \\
1,111.05\end{array}$} \\
\hline & 250.14 & 384.25 & 458.05 & \\
\hline SCN 7 & 250.14 & 384.25 & 455.65 & 978.05 \\
\hline SCN 6 & 250.14 & 384.25 & 454.55 & $1,090.85$ \\
\hline SCN 5 & 250.14 & 384.25 & 454.55 & 971.55 \\
\hline SCN 4 & 250.14 & 384.25 & 456.85 & $1,044.55$ \\
\hline $\operatorname{SCN} 3$ & 250.14 & 384.25 & 454.55 & $1,031.15$ \\
\hline $\mathrm{SCN} 2$ & 250.14 & 384.25 & 454.55 & $1,015.45$ \\
\hline SCN1 & 250.14 & 384.27 & 454.52 & 915.54 \\
\hline
\end{tabular}

Figure 4. Comparison of 3 customer groups: Current tariff (Scn1) versus seven simulated IIBT ( $\operatorname{Scn} 2-\operatorname{Scn} 8)$

\section{DISCUSSION \& CONCLUSION}

The IBT was tested using 3 different low / high water use blocks: 70/30, 80/20; and 90/10. Based on the social survey of approximately 800 Gold Coast customers prior in the year, the $80 / 20$ configuration was the most preferred and is thus recommended as a starting point for COGC. The SDM for tariff modelling using the COGC data clearly demonstrates that high water users will get 'penalised' for using excess volumes of water, which is driven typically from outdoor water use activities (e.g. irrigation), based on previous research in SEQ (Beal and Stewart 2011). This would provide a disincentive for high water users to reduce their use, or pay considerably more for the 'luxury' of consuming such large volumes of water (e.g. $>400 \mathrm{~kL} / \mathrm{hh} / \mathrm{y}$ ). The user pays system (IBT) is recognised as a successful water demand management and water conservation strategy whereby reducing household costs are an incentive for water efficiency. The following conclusions were derived from the tariff modelling exercise:

- $\quad$ The IBT approach is a well-accepted method for penalising high water use customers to reduce their water rather than restrictions across the board;

- The preferred proportion of customers to be affected by the second, higher water price was $20 \%$ based on the social survey respondents. This means that $80 \%$ of COGC residential customers will not be affected by an IBT tariff structure when implemented;

- Based on an 80/20 tier (scenario 3), the first billing period after introduction would see the block two customers paying approximately $\$ 100$ extra on their bill.

- Revenue neutrality can be achieved using an IBT by determining the feedback of customers to the higher cost. Modelling suggests that after two years of introducing the IBT, and assuming no price 
Sahin et al., A modelling framework for assessing water conservation potentials through demand-based tariff structures

increase during this time, demand from the $20 \%$ of high water users will start rebounding and will return to pre-IBT consumption;

- At the discretion of council there may be the option of using any surplus revenue from the B2 customers to subsidise households that also fall into the B2 category and have difficulty avoiding high water use (e.g. medical reasons, large family, home business);

- There is also an opportunity for council to vary the proportion of customers that are charged the second block tariff during dry and wet seasons; and

- Due to the changes in frequency of billing notices (from 6 monthly to quarterly), the signals to customers can be sent much more quickly, i.e. the impact on demand through ;pricing signals from a two-tiered structure will be quicker and easier to forecast (both revenue and demand).

\section{REFERENCES}

Beal, C. \& Stewart, R. A. 2011. South East Queensland Residential End Use Study: Final Report. Urban Water Security Research Alliance Technical Report No. 47. Gold Coast, Australia.

Brandes, O. M., Renzetti, S. \& Stinchcombe, K. 2010. Worth Every Penny: A Primer on Conservation-Oriented Water Pricing. POLIS Project on Ecological Governance. Victoria, BC, Canada: University of Victoria.

Dalhuisen, J. M., Florax, R. J. G. M., de Groot, H. L. F. \& Nijkamp, P. 2003. Price and income elasticities of residential water demand: A meta-analysis. Land Economics, 79, 292-308.

Espey, M., Espey, J. \& Shaw, W. D. 1997. Price elasticity of residential demand for water: A metaanalysis. Water Resources Research, 33, 1369-1374.

Fiddaman, T. S. 2002. Exploring policy options with a behavioral climate-economy model. System Dynamics Review, 18, 243-267.

Ford, A. 1999. Modelling the Environment: An Introduction to System Dynamics Modelling of Environment Systems, Washington DC, USA, Island Press, pp.

Forrester, J. W. 1961. Industrial dynamics, Cambridge, Mass, MIT Press, pp.

Frontier Economics. 2008. Approaches to urban water pricing. Waterlines occasional paper no 7. Canberra, A.C.T.: National Water Commission.

Hamilton, S. H., ElSawah, S., Guillaume, J. H. A., Jakeman, A. J. \& Pierce, S. A. 2015. Integrated assessment and modelling: Overview and synthesis of salient dimensions. Environmental Modelling \& Software, 64, 215-229.

Langsdale, S., Beall, A., Carmichael, J., Cohen, S., Forster, C. \& Neale, T. 2009. Exploring the Implications of Climate Change on Water Resources through Participatory Modeling: Case Study of the Okanagan Basin, British Columbia. Journal of Water Resources Planning and Management, 135(5), 373-381.

NWC 2011. Review of pricing reform in the Australian water sector 2011. Canberra, A.C.T.: National Water Commission.

Porter, M. G., Downie, D., Scarborough, H., Sahin, O. \& Stewart, R. A. 2014. Drought and Desalination: Melbourne water supply and development choices in the twenty-first century. Desalination and Water Treatment, 10.1080/19443994.2014.959743, 1-18.

QCA. 2014. Position Paper: Pricing principles for south east Queensland water retailers [Online]. The Queensland Competition Authority. Available: http://www.qca.org.au/water [Accessed June 2015.

Sahin, O., Mohamed, S., 2013. A spatial temporal decision framework for adaptation to sea level rise. Environmental Modelling \& Software, In Press.

Sahin, O., Siems, R. S., Stewart, R. A. \& Porter, M. G. 2014. Paradigm shift to enhanced water supply planning through augmented grids, scarcity pricing and adaptive factory water: A system dynamics approach. Environmental Modelling \& Software, 10.1016/j.envsoft.2014.05.018.

Sahin, O., Stewart, R. A. \& Porter, M. G. 2015. Water security through scarcity pricing and reverse osmosis: a system dynamics approach. Journal of Cleaner Production, 88, 160-171.

Scarborough, H., Sahin, O., Porter, M. \& Stewart, R. 2015. Long-term water supply planning in an Australian coastal city: Dams or desalination? Desalination, 358, 61-68.

Sterman, J. D. 2000. Business Dynamics: Systems Thinking and Modeling for a Complex World, NY, USA, Irwin/McGraw-Hill, pp.

Sterman, J. D. 2008. Economics - Risk communication on climate: Mental models and mass balance. Science, 322, 532-533.

Van den Belt, M., Dietz, T., van den Belt, M. \& ebrary Inc. 2004. Mediated modeling : a system dynamics approach to environmental consensus building, Washington, DC, Island press, pp.

Whittington, D. 2003. Municipal water pricing and tariff design: a reform agenda for South Asia. Water Policy, 5, 61-76. 